\title{
Híbridos de Sorgo (Sorghum bicolor (L.) Moench) Cultivados sob Níveis Crescentes de Adubação. Características Agronômicas, Carboidratos Solúveis e Estruturais da Planta ${ }^{1}$
}

\author{
Miguel Marques Gontijo Neto ${ }^{2}$, José Antônio Obeid ${ }^{3}$, Odilon Gomes Pereira ${ }^{3}$, Paulo Roberto \\ Cecon ${ }^{4}$, Augusto César de Queiroz ${ }^{3}$, Cláudio Prates Zago ${ }^{5}$, Magno José Duarte Cândido ${ }^{6}$, \\ Lídia Ferreira Miranda
}

\begin{abstract}
RESUMO - Foram avaliadas características agronômicas, fibra em detergente neutro (FDN), fibra em detergente ácido (FDA) e carboidratos solúveis e estruturais de cinco híbridos de sorgo forrageiro (AG-2002, AG-2005E, AGX-202, AGX-213 e AGX-215), cultivados sob quatro níveis de adubação NPK. Utilizou-se o delineamento em blocos casualizados, em esquema fatorial 5 x 4 , com quatro repetições. As médias dos fatores qualitativos foram comparadas pelo teste de Tukey a 5 e 1\% de probabilidade. Os híbridos avaliados apresentaram diferentes proporções de colmos (29,01 a 53,38\%), de folhas (16,70 a 22,64\%) e de panículas (29,91 a 52,43\%), sendo colmos e panículas fortemente correlacionadas com altura, $0,79 * *$ e $-0,82 * *$, respectivamente. O teor de matéria seca (MS) da planta inteira foi fortemente influenciado pelas proporções de colmos e panículas, tendo as panículas apresentado os maiores teores de MS (48,79 a 56,80\%) e colmos as menores (18,86 a 22,54\%). O aumento nos níveis de adubação proporcionou acréscimo na produção de panículas, que refletiu na diminuição da relação colmo + folha/panícula, no acréscimo da proporção de panículas e no teor de MS da planta inteira. Os teores de carboidratos solúveis totais, com base na matéria seca, variaram entre os híbridos avaliados (12,24 a 19,80\%) e apresentaram aumento com a elevação dos níveis de adubação. Os híbridos avaliados apresentaram diferenças significativas entre os teores de fibra em detergente neutro (57,38 a 62,30\%), fibra em detergente ácido (25,29 a 31,56\%), hemicelulose (28,56 a 33,87\%), celulose (19,20 a 24,34\%) e lignina (6,04 a 6,51\%). O avanço nos níveis de adubação resultou em queda nos teores de FDN e hemicelulose.
\end{abstract}

Palavras-chave: características agronômicas, forragem, sorgo forrageiro

\section{Sorghum (Sorghum bicolor (L.) Moench) Hybrids Cultivated under Increasing Fertilization Levels. Agronomic Characteristics, Soluble and Structural Carbohydrates of the Plant}

\begin{abstract}
The agronomic characteristics, neutral detergent fiber (NDF), acid detergent fiber (ADF) and total soluble and structural carbohydrates contents of five hybrid sorghum (AG-2002, AG-2005E, AGX-212, AGX-213 e AGX-215), cultivated under different fertilization levels, were evaluated. A randomized blocks design, in a 5 x 4 factorial scheme, with four replicates, was used. The qualitative factors means were analyzed by means of Tukey test at 5 and $1 \%$ of probability. The evaluated hybrids showed different proportions of stem (29.01 to 53.38\%), leaves (16.70 to $22.64 \%$ ) and panicle (29.91 to $52.43 \%$ ), where stem and panicle were highly correlated with height, $0.79 * *$ and $-0,82 * *$, respectively. Dry matter content of whole plant was strongly affected by stem and panicle proportion, where the panicle showed higher DM contents (48.79 to 56,80\%) and stem, the smaller (18.86 to 22.54\%). The increase in the fertilization levels provided increment in the panicle production, that decreased stem+leaves/panicle proportions and increased panicle proportion and DM content of whole plant. The total soluble carbohydrates contents, in dry matter basis, varied among evaluated hybrids (12.24 to 19.80\%) and increased as the fertilization levels increased. The evaluated hybrids showed significant differences among the NDF (57.38 to 62.30), ADF (25.29 to 31.56\%), hemicellulose (28.56 to 33.87\%), cellulose (19.20 to 24.34\%) and lignin (6.04 a 6.51\%) contents. The NDF and hemicellulose contents decreased as the fertilization levels increased.
\end{abstract}

Key Words: agronomic characteristics, forage, forage sorghum

\section{Introdução}

Durante muitos anos, os cultivares de sorgo para ensilagem foram indicados com base apenas na pro- dução de matéria verde por hectare, no intuito de reduzir o custo da tonelada de matéria verde produzida, sem considerar a qualidade desse material. Os cultivares usados há 20 ou 25 anos caracterizavam-se

\footnotetext{
${ }^{1}$ Parte da tese de mestrado do primeiro autor financiada pela FAPEMIG.

2 Pesquisador Embrapa Gado de Corte, CP 154, CEP: 79002-970, Campo Grande-MS (mgontijo@cnpgc.embrapa.br).

3 Prof. Depto. de Zootecnia/UFV. Av. P. H. Rolfs, s/n, 36.571-000, Viçosa-MG (jaobeid@ufv.br; odilon@ufv.br; aqueiroz@ufv.br).

4 Prof. Depto. de Informática/UFV (cecon@dpi.ufv.br).

5 Pesquisador da Dow-Agroscience.

${ }^{6}$ Professor do Depto. de Zootecnia/UFC (magno@ufc.br).

${ }^{7}$ Professora FEAD-MG, Belo Horizonte, MG (lidia.miranda@fead.br).
} 
por porte alto, ciclo longo e baixa produção de grãos. Com a utilização de animais mais exigentes, passou-se a dar maior importância à presença de grãos no material a ser ensilado, sendo este o critério que tem prevalecido nos últimos anos.

A proporção de grãos é um importante fator relacionado à qualidade das silagens, porque neles encontra-se a maior fração energética disponível da planta e porque são responsáveis pela maior elevação no teor de matéria seca da massa ensilada, em função de seu menor conteúdo de água. Em sorgo, o potencial de produção de MS aumenta e a porcentagem de panícula decresce com o aumento da altura da planta, sendo esta taxa de decréscimo menor nos híbridos de portes baixo e médio e maior quando a altura da planta excede três metros (Zago, 1991).

Gourley \& Lusk (1977) encontraram porcentagens de colmo na planta de sorgo de 17,1 a 72,8\% na MS, proporções de folhas de 17,4 a $26,3 \%$ e de panículas de 5,2 a 64,6\%. Schimid et al. (1976) registraram relação colmo: folha:panícula, na MS, de 31:20:49 e 57:28:15 para sorgos tipo granífero e forrageiro, respectivamente. Bruno et al. (1992) encontraram, para sorgos forrageiros e de duplo propósito, porcentagens de colmo, folha e panícula, na MS, de 65,$8 ; 22,6$ e 11,6 e 38,5; 37,7 e 23,8\%, respectivamente. Borges (1995), trabalhando com sorgos de porte alto, registrou proporções de colmo, folhas e panícula de 59,9 a $64 \%$, de 12,7 a $14,5 \%$ e de 22,2 a $27,1 \%$, respectivamente.

O conteúdo de açúcares das forragens é importante para sua palatabilidade e adequação à ensilagem, sendo marcadamente afetado pelas condições ambientais (Haig, 1990; Van Soest, 1994), pelos cultivares, pelo estádio de crescimento, pelo espaçamento de plantio (McBee \& Miller, 1982) e pelos níveis de fertilização (McDonald et al., 1991).

Os carboidratos solúveis (glicose, frutose, sacarose e frutosanas) são o principal substrato para a fermentação no silo (Henderson, 1993) e sua concentração determina os parâmetros de qualidade das silagens (Petterson \& Linderen, 1989). No processo fermentativo normal, estes carboidratos são convertidos a ácidos orgânicos, principalmente ácido lático, provocando a queda do $\mathrm{pH}$, que inibea ação de outros microorganismos, sobretudo o Clostridium, e a proteólise pelas enzimas das plantas (McDonald et al., 1991).

Johnson et al. (1973), trabalhando com sorgo, registraram $15 \%$ como o teor mínimo de carboidratos solúveis necessário para formação adequada de ácido lático. Obeid et al. (1992), por sua vez, detectaram 13,8\% em plantas de milho. Segundo McCullough (1973), citado por Gourley \& Lusk (1977), são necessários, para boa fermentação, 6 a 8\% de carboidratos solúveis. Outros pesquisadores, ao trabalharem com teores de carboidratos solúveis com base no material original, recomendam valores mínimos de 2,5 a 3\% da matéria verde de CHO solúveis (Petterson \& Lindgren, 1989; Wilkinson, 1983).

Segundo Minson (1990) e Van Soest (1994), a digestibilidade e o consumo da forragem são determinantes de seu valor para a produção animal e, como são de difícil determinação, o uso das frações fibrosas e da técnica de digestibilidade in vitro para estimá-los pode ser de grande utilidade. As frações FDN, FDA e lignina são negativamente correlacionadas à digestibilidade e, conseqüentemente, ao valor energético das forragens (Minson, 1990). Além disso, os valores de FDN das forragens são negativamente correlacionados ao consumo das mesmas e, desta forma, forragens originárias de híbridos de sorgo de menor concentração de FDN apresentariam maiores taxas de consumo voluntário, desde que não houvesse outros fatores envolvidos (Van Soest, 1994).

Teores de FDN, em forragem fresca de sorgo, variando de 51,6 a $67,4 \%$; de FDA, de 28,7 a $45,6 \%$; de hemicelulose, de 20,8 a $38,1 \%$; de celulose, de 23,0 a $36,5 \%$; e de lignina, de 1,86 a $8,0 \%$, encontram-se relatados em diversos trabalhos (Gontijo Neto, 2000).

Uma das formas de aumentar a produtividade e a qualidade nutricional de uma forrageira é, sem dúvida, a nutrição mineral adequada, por intermédio de programas de adubação que considerem, além da quantidade de fertilizantes fornecida, o balanço entre os nutrientes requeridos. Assim, a análise de solo é uma ferramenta essencial para orientar a adubação. Krantz \& Chandler (1951), citados por Malavolta \& Dantas (1987), comprovaram que a relação grãos/folhas + colmos no milho pode aumentar de 1:3 para 1:1 com maiores doses de nitrogênio $(\mathrm{N})$ aplicadas.

Este trabalho foi realizado com o objetivo de avaliar as variações dos teores de carboidratos solúveis e estruturais, da altura, da produção, da proporção e dos teores de MS de colmo, folhas e panículas de cinco híbridos de sorgo cultivados sob níveis crescentes de adubação. 


\section{Material e Métodos}

O experimento foi conduzido no período de 06/11/1997 a 18/02/1998, nas dependências da Central de Experimentação, Pesquisa e Extensão do Triângulo Mineiro (CEPET/UFV), no município de Capinópolis-MG, com latitude de $18^{\circ} 41^{\prime}$ S e longitude de $49^{\circ} 34^{\prime} \mathrm{W}$ e altitude média de $620,20 \mathrm{~m}$. O clima é o Aw, segundo classificação de Köppen, quente e úmido, com temperatura do mês mais frio acima de $18^{\circ} \mathrm{C}$ (A) e estação chuvosa no verão e seca no inverno (w). Apresenta precipitações médias anuais entre 1.400 e $1.600 \mathrm{~mm}$. Os dados relativos a temperatura e pluviosidade no período experimental são apresentados na Tabela 1.

A área experimental apresenta relevo suave ondulado e solo classificado como Latossolo Roxo eutrófico, de textura argilosa, desenvolvido a partir do basalto. A área onde foi instalado o experimento foi utilizada em ensaios com soja nos anos anteriores.

Em função da análise do solo (Tabela 2) e com base na recomendação obtida pelo método do $\mathrm{Al}^{3+}$, $\mathrm{Ca}^{2+}$ e $\mathrm{Mg}^{2+}$ trocáveis (COMISSÃO DE FERTILIDADE DO SOLO DO ESTADO DE MINAS GERAIS, 1989), foram incorporados $400 \mathrm{~kg} / \mathrm{ha}$ de calcário (PRNT=75\%) ao solo.
O preparo do solo consistiu de uma aração e duas gradeações, para destorroamento e nivelamento, sendo a abertura dos sulcos, distribuição e incorporação do adubo e das sementes efetuadas manualmente. A adubação recomendada para plantio e cobertura baseou-se na análise do solo seguindo as "Recomendações Para o Uso de Corretivos e Fertilizantes em Minas Gerais” (COMISSÃO DE FERTILIDADE DO SOLO DO ESTADO DE MINAS GERAIS, 1989), com pequena variação decorrente da utilização de formulações comerciais existentes, e consistiu de $350 \mathrm{~kg} / \mathrm{ha}$ da fórmula (NPK) 06-28-08 no plantio mais $350 \mathrm{~kg} / \mathrm{ha}$ de sulfato de amônio em cobertura, divididos em duas parcelas iguais, correspondendo a uma recomendação total de $350 \mathrm{~kg}$ da fórmula (NPK) 26-28-08.

Foi utilizado delineamento experimental em blocos casualizados, em esquema fatorial $5 \times 4$ (cinco híbridos x quatro níveis de adubação), com quatro repetições. Os híbridos utilizados foram os seguintes: 1- AG-2002, forrageiro, porte alto, colmo suculento e população recomendada de 125.000 plantas/ha; 2- AG-2005-E, duplo propósito, porte baixo, colmo seco e população recomendada de 150.000 plantas/ha; 3- AG-X-202, forrageiro, porte alto, colmo seco e população recomendada de 125.000 plantas/ha;

Tabela 1 - Precipitação e médias das temperaturas máximas e mínimas durante o período experimental Table 1 - Rainfall and average maximum and minimum temperatures during the experimental period

\begin{tabular}{|c|c|c|c|c|}
\hline \multirow[t]{2}{*}{$\begin{array}{l}\text { Período } \\
\text { Period }\end{array}$} & \multirow[t]{2}{*}{$\begin{array}{l}\text { Semana } \\
\text { Week }\end{array}$} & \multirow[t]{2}{*}{$\begin{array}{c}\text { Precipitação }^{1}(\mathrm{~mm}) \\
\text { Rainfall }\end{array}$} & \multicolumn{2}{|c|}{$\begin{array}{c}\text { Temperatura }\left({ }^{\circ} \mathrm{C}\right)^{2} \\
\text { Temperature }\end{array}$} \\
\hline & & & $\begin{array}{l}\text { Máxima } \\
\text { Maximum }\end{array}$ & $\begin{array}{l}\text { Mínima } \\
\text { Minimum }\end{array}$ \\
\hline 06/11/97 a 12/11/97 & $1^{\mathrm{a}}$ & 17,0 & 34,8 & 21,9 \\
\hline 13/11/97 a 19/11/97 & $2^{\mathrm{a}}$ & 62,4 & 32,3 & 20,9 \\
\hline 20/11/97 a 26/11/97 & $3^{\mathrm{a}}$ & 80,8 & 32,1 & 20,9 \\
\hline 27/11/97 a 03/12/97 & $4^{\mathrm{a}}$ & 188,6 & 30,0 & 21,0 \\
\hline 04/12/97 a 10/12/97 & $5^{a}$ & 67,2 & 28,9 & 20,2 \\
\hline 11/12/97 a 17/12/97 & $6^{\mathrm{a}}$ & 65,3 & 30,5 & 21,0 \\
\hline 18/12/97 a 24/12/97 & $7^{\mathrm{a}}$ & 8,7 & 30,5 & 20,9 \\
\hline 25/12/97 a 31/12/97 & $8^{a}$ & 60,7 & 33,8 & 21,8 \\
\hline 01/01/98 a 07/01/98 & $9^{\mathrm{a}}$ & 12,7 & 34,5 & 21,8 \\
\hline 08/01/98 a 14/01/98 & $10^{\mathrm{a}}$ & 102,2 & 31,6 & 21,9 \\
\hline 15/01/98 a 21/01/98 & $11^{\mathrm{a}}$ & 40,8 & 30,8 & 20,8 \\
\hline $22 / 01 / 98$ a $28 / 01 / 98$ & $12^{\mathrm{a}}$ & 22,0 & 30,8 & 20,4 \\
\hline 29/01/98 a 04/02/98 & $13^{\mathrm{a}}$ & 46,8 & 31,1 & 21,8 \\
\hline 05/02/98 a 11/02/98 & $14^{\mathrm{a}}$ & 62,6 & 34,2 & 21,8 \\
\hline $12 / 02 / 98$ a $18 / 02 / 98$ & $15^{\mathrm{a}}$ & 92,7 & 30,8 & 21,8 \\
\hline
\end{tabular}

\footnotetext{
${ }^{1}$ Total do período (Total of the period).
}

${ }^{2}$ Média do período (Mean of the period).

R. Bras. Zootec., v.33, n.6, p.1975-1984, 2004 (Supl. 2) 
Tabela 2 - Resultado da análise do solo da área experimental Table 2 - Soil analysis of the experimental area

\begin{tabular}{|c|c|c|c|c|c|c|c|c|c|c|}
\hline \multirow{2}{*}{$\begin{array}{l}\text { Profundidade }(\mathrm{cm}) \\
\text { Depth }\end{array}$} & \multirow[t]{2}{*}{$\mathrm{pH}$} & \multirow{2}{*}{\multicolumn{2}{|c|}{$\begin{array}{l}\mathrm{P} \\
-\mathrm{mg} / \mathrm{dm}^{3}-\end{array}$}} & $\mathrm{Ca}$ & $\mathrm{Mg}$ & SB & $\mathrm{H}+\mathrm{Al}$ & СTC & $\mathrm{Al}$ & V \\
\hline & & & & \multicolumn{6}{|c|}{$-\mathrm{cmol} / \mathrm{dm}^{3}$} & -\% - \\
\hline $0-20$ & 5,6 & 9,8 & 83 & 3,1 & 1,2 & 4,51 & 5,0 & 9,51 & 0,1 & 47,4 \\
\hline $20-40$ & 5,6 & 6,0 & 29 & 3,0 & 1,0 & 4,00 & 5,2 & 9,26 & 0,0 & 43,8 \\
\hline
\end{tabular}

4 - AG-X-213, forrageiro, porte alto, colmo seco e população recomendada de 125.000 plantas/ha; 5 - AG-X-215, forrageiro, porte médio/alto, colmo seco e população recomendada de 150.000 plantas/ ha, sendo os dois primeiros comerciais e os três últimos em fase experimental. Os níveis de adubação utilizados no experimento foram: 1 - sem adubação de plantio e cobertura, 2 - metade da adubação recomendada para plantio e coberturas, 3 - uma vez a adubação recomendada, 4 - duas vezes a adubação recomendada.

As parcelas experimentais constituíram-se de seis fileiras, com 5,0 metros de comprimento, espaçadas entre si a 0,8 metros, devidamente identificadas. Em cada parcela, foram utilizadas para amostragem, as duas fileiras centrais, descontadas de 0,5 metros em cada extremidade, resultando em área útil de $6,4 \mathrm{~m}^{2}$ (4,0 m x 0,8 m x 2 fileiras).

O plantio foi realizado em 06/11/1997 e, 10 dias após a emergência, foi efetuado o desbaste nas parcelas, para se chegar à população de plantas por hectare recomendada para cada híbrido. Aos 20 e 35 dias após a emergência, foram realizadas as adubações de cobertura nos tratamentos em que estas ocorreram. Foi realizada capina manual aos 20 dias após a emergência.

Procedeu-se à colheita quando as plantas atingiram o estádio de grãos farináceos. As plantas da área útil das parcelas foram medidas em relação a altura e cortadas a $15 \mathrm{~cm}$ do solo. Foram retiradas 20 plantas por parcela, para determinação da relação colmo/folhas/panícula, por meio de pesagem, e retirada de amostras de cada fração de aproximadamente 400 g, para determinação da matéria seca, e de 10 plantas inteiras, que foram picadas em picadeira 'Nogueira modelo DPM 2', homogenizadas, e retiradas amostras de aproximadamente $400 \mathrm{~g}$. As amostras provenientes do material foram secas em estufa de ventilação forçada a $65^{\circ} \mathrm{C}$, durante 72 horas. Após a retirada da estufa e permanência das amostras em condições ambientes, por cerca de 1 hora, as mesmas foram pesadas, processadas em moinho Willey (peneira com malha de $1 \mathrm{~mm}$ ) e acondicionadas em vidros de $200 \mathrm{ml}$ com tampa de polietileno. As amostras secas ao ar (ASA) da planta inteira, colmos, folhas e panículas, devidamente acondicionadas, foram transportadas para as dependências do Departamento de Zootecnia da Universidade Federal de Viçosa, em Viçosa,MG, onde foram determinados o teor de matéria seca (MS), em estufa a $105^{\circ} \mathrm{C}$, conforme a recomendação da AOAC (1984), e os componentes da parede celular, pelo método seqüencial, segundo Van Soest \& Wine (1968) e carboidratos solúveis, extraídos por fervura em água e dosados por colorimetria, segundo Deriaz (1961), descritos por Silva (1990).

Os dados foram interpretados por meio de análises de variância e de regressão, segundo o modelo estatístico:

$$
Y_{i j k}=m+B_{i}+H_{j}+A_{k}+H_{j k}+e_{i j k}
$$

em que: $Y_{i j k}=$ observação referente à parcela do bloco i, com o híbrido j e com o nível de adubação k; $\mathrm{m}=$ média geral; $\mathrm{B}_{\mathrm{i}}=$ efeito do bloco $\mathrm{i}(\mathrm{i}=1,2,3,4)$; $\mathrm{H}_{\mathrm{j}}=$ efeito do híbrido $\mathrm{j}(\mathrm{j}=1,2,3,4,5) ; \mathrm{A}_{\mathrm{k}}=$ efeito do nível de adubação $\mathrm{k}(\mathrm{k}=1,2,3,4) ; \mathrm{HA}_{\mathrm{jk}}=$ efeito da interação híbrido x nível de adubação; e $\mathrm{e}_{\mathrm{ijk}}=$ variação aleatória (erro experimental).

As médias dos fatores qualitativos foram comparadas utilizando o teste Tukey, a 5 e 1\% de probabilidade. Os modelos foram escolhidos com base na significância da regressão e da falta de ajustamento, testadas pelo teste F, na significância dos coeficientes de regressão, utilizando-se o teste de Student " $t$ ", a $5 \%$ e $1 \%$ de probabilidade, e no coeficiente de determinação. Foram determinadas correlações simples, aplicando-se o teste de Pearson, a 5 e $1 \%$ de probabilidade. Como auxiliar nas análises estatísticas, utilizou-se o programa de Análises Estatística e Genética (SAEG, 1995), desenvolvido pela UFV. 
Tabela 3 - Médias de altura (ALT); relação colmo + folhas/panículas (CF/P); teores de MS da planta inteira (MS), de colmo (MSC), de folhas (MSF) e de panículas (MSP); produção (t/ha) de colmos (PSC), de folhas (PSF) e de panículas (PSP); e porcentagens na MS de colmos (\%C), de folhas (\%F) e de panículas (\%P) dos híbridos avaliados

Table 3 - Means of height (ALT); stem+leaves/panicle ratio (CF/P); DM content of the whole plant (MS) yield of stem (PSC), leaves $(P S F)$ and panicle (PSP); DM stem percentage (\%C), leaves (\%F) and panicle (\%P); and DM contents of stem (MSC), leaves (MSF) and of panicle (MSP) of the evaluated hybrids

\begin{tabular}{|c|c|c|c|c|c|}
\hline \multirow[t]{2}{*}{$\begin{array}{l}\text { Variável } \\
\text { Variable }\end{array}$} & \multicolumn{5}{|c|}{$\begin{array}{l}\text { Híbridos } \\
\text { Hybrids }\end{array}$} \\
\hline & AG-2002 & AG-2005E & AGX-212 & AGX-213 & AGX-215 \\
\hline Altura (m) & $3,57^{\mathrm{A}}$ & $2,14^{\mathrm{D}}$ & 3,47 B & $3,42^{B}$ & $3,05^{\mathrm{C}}$ \\
\hline Height & & & & & \\
\hline $\mathrm{CF} / \mathrm{P}$ & $2,35^{A}$ & $0,91^{\mathrm{C}}$ & $1,60^{\mathrm{B}}$ & $1,76^{\mathrm{B}}$ & $1,79^{\mathrm{B}}$ \\
\hline MS (\%) & $24,72^{\mathrm{D}}$ & $31,43^{\mathrm{A}}$ & 29,84 AВ & $27,19^{\mathrm{C}}$ & $28,81^{\mathrm{BC}}$ \\
\hline MSC (\%) & $18,86^{\mathrm{B}}$ & $20,50^{\mathrm{AB}}$ & $22,54^{\mathrm{A}}$ & $20,56^{\mathrm{AB}}$ & $20,99^{A}$ \\
\hline MSF (\%) & $25,78^{\mathrm{B}}$ & $25,73^{\mathrm{B}}$ & $31,57^{\mathrm{A}}$ & $33,17^{\mathrm{A}}$ & $32,53^{A}$ \\
\hline MSP (\%) & $56,80^{A}$ & $48,79^{\mathrm{B}}$ & $53,78^{\mathrm{AB}}$ & $54,42 \mathrm{AB}$ & 50,37 B \\
\hline $\operatorname{PSC}(\mathrm{t} / \mathrm{ha})$ & $10,17^{\mathrm{a}}$ & $3,64^{d}$ & $6,53^{b}$ & $7,16^{\mathrm{b}}$ & $5,79^{\mathrm{c}}$ \\
\hline $\operatorname{PSF}(\mathrm{t} / \mathrm{ha})$ & $3,13^{a}$ & $2,32^{b}$ & $3,39^{a}$ & $3,51^{\mathrm{a}}$ & $3,31^{\mathrm{a}}$ \\
\hline PSP (t/ha) & $5,41^{b}$ & $6,75^{\mathrm{a}}$ & $6,29^{a}$ & $6,07^{a b}$ & $5,51^{b}$ \\
\hline$\% \mathrm{C}$ & $53,38^{A}$ & $29,01^{\mathrm{C}}$ & $40,34^{\mathrm{B}}$ & $42,68^{\mathrm{B}}$ & $39,62^{\mathrm{B}}$ \\
\hline$\% \mathrm{~F}$ & $16,70^{\mathrm{C}}$ & $18,56^{\mathrm{BC}}$ & $20,88^{A B}$ & $20,96^{A}$ & $22,64^{\mathrm{A}}$ \\
\hline$\% \mathrm{P}$ & $29,91^{\mathrm{C}}$ & $52,43^{\mathrm{A}}$ & $38,78^{\mathrm{B}}$ & $36,30^{\mathrm{B}}$ & $37,62^{\mathrm{B}}$ \\
\hline
\end{tabular}

Médias, nas linhas, seguidas por letras distintas, diferem pelo teste de Tukey, minúsculas $(P<0,05)$ e maiúsculas $(P<0,01)$.

Means, within a row, followed by different letters, differ by Tukey test, small $(P<.05)$ and capital $(P<.01)$.

\section{Resultados e Discussão}

Os períodos entre a semeadura e colheita dos híbridos avaliados foram de 92 dias para o AG-2005E, de 99 dias para o AGX-215 e de 106 dias para os híbridos AG-2002, AGX-202 e AGX-213, com tendência dos híbrido de maior porte se apresentarem mais tardios.

Os valores médios registrados para altura (ALT); relação colmo + folhas/panículas (CF/P); teor de MS da planta inteira (MS), de colmo (MSC), de folhas (MSF) e de panícula (MSP); produção de colmos (PSC), de folhas (PSF) e de panículas (PSP); porcentagens na MS de colmos (\%C), de folhas (\%F) e de panículas (\%P); e teores de MS dos híbridos avaliados encontram-se na Tabela 3. Não foi verificada diferença $(\mathrm{P}>0,05)$ para a interação dos fatores híbrido $\mathrm{X}$ adubação para nenhuma das variáveis analisadas.

O teor de MS da forragem é a relação entre as proporções e os teores de MS dos componentes da planta. O AG-2002 apresentou teores de MS pouco abaixo dos níveis recomendados para ensilagem (24,72\%), enquanto os demais híbridos apresentaram teores de 27,19 a 31,43\%, dentro da faixa recomendada (27 a 38\%) por Faria (1986) e Zago (1991).

Houve grande variação nos teores de MS entre as partes da planta. Nos colmos, nas folhas e panículas os teores de MS variaram de 18,86 a 22,$54 ; 25,73$ a 33,17; e 48,79 a 56,80\%, respectivamente. Também foram registradas variações significativas entre os híbridos quando analisadas a mesma parte da planta, destacando-se o baixo teor de MS do colmo do AG2002 (18,86\%), possivelmente por seu caráter suculento, mesmo apresentando o maior teor de MS para panículas (56,80\%).

As proporções das partes da planta, avaliadas com base na MS, apresentaram grandes variações entre os híbridos, com valores de 29,01 a 53,38\% (variação de 24,37 pontos percentuais) para colmos, de 29,91 a $52,43 \%$ (22,52 pontos percentuais) para panículas e de 16,70 a $22,64 \%$ para folhas, com menores variações (5,94 pontos percentuais).

Os híbridos de porte alto apresentaram diferenças $(P<0,01)$ para altura, porém estas variações, em valores absolutos, foram em torno de $10 \mathrm{a} 15 \mathrm{~cm}$, sem maior importância prática. Entretanto, ressaltam-se as maiores participações de panículas e menores de colmos nos híbridos de porte alto AGX-212 e AGX213 em relação ao AG-2002. Corroborando os resultados obtidos por Zago (1991), a produção de MS e a porcentagem de colmo aumentaram, enquanto a porcentagem de panícula decresceu com o avanço da altura da planta. Observaram-se altas correlações entre altura da planta e produção de MS $\left(0,794^{* *}\right)$, 
proporção de colmos $(0,790 * *)$ e panículas $(-0,824 * *)$ no presente trabalho.

Analisando-se os teores de MS da planta inteira, observou-se que as variações nas proporções de partes da planta dos híbridos avaliados, principalmente as porcentagens de colmos e panículas, exerceram maior influência sobre o teor de MS da planta inteira que teor de umidade de cada uma dessas frações. Esta hipótese torna-se mais clara ao se analisarem os híbridos AG-2002 (24,72\%) e AG-2005E (31,43\%), que apresentaram os teores de umidade extremos. No caso das panículas, que têm maiores teores de MS e tendem a elevar o teor de MS da planta, o AG-2002, mesmo com teor de MS maior $(\mathrm{P}<0,01)$ que o AG2005E, por apresentar menor proporção de panículas resultando em menor teor de MS na planta inteira. Raciocínio contrário aplica-se aos colmos, que, com os menores teores de MS da planta, contribuem para redução do teor de MS de planta inteira. Mesmo que os híbridos tenham apresentado teores de MS de colmo estatisticamente iguais, a maior participação deste componente no AG-2002 refletiu elevando o teor de umidade da planta inteira. O estudo das correlações lineares entre o teor de MS da planta inteira eproporções de colmos $\left(-0,72^{* *}\right)$, folhas $\left(0,18^{\mathrm{ns}}\right)$ e panículas $\left(0,68^{* *}\right)$ também apontou neste sentido.

As proporções de colmo, folhas e panícula dos híbridos avaliados originaram valores de relação colmo + folhas/panícula diferentes $(\mathrm{P}<0,01)$, com o AG-2002 apresentando a maior relação $(2,35)$ e o AG-2005E, a menor $(0,91)$. O estudo da relação $\mathrm{CF} / \mathrm{P}$ permite verificar claramente o desempenho

Tabela 4 - Equações de regressão estimadas para a produção de matéria seca de colmos (PSC), folhas (PSF) e panículas (PSP) dos híbridos avaliados, em função dos níveis de adubação (A), e coeficientes de determinação

Table 4 - Regression equations estimated for dry matter yield of stem (PSC), leaves (PSF) and panicle $(P S P)$ of the evaluated hybrids, according to the fertilization levels (A), and coefficients of determination

\begin{tabular}{lcc}
\hline $\begin{array}{l}\text { Variáveis } \\
\text { Variables }\end{array}$ & $\begin{array}{c}\text { Equações de regressão } \\
\text { Regression equations }\end{array}$ & $\mathrm{r}^{2}$ \\
\hline PSC (t/ha) & $\hat{\mathrm{Y}}=6,6605$ & \\
PSF (t/ha) & $\hat{\mathrm{Y}}=3,1304$ \\
$\mathrm{PSP}(\mathrm{t} / \mathrm{ha}) \hat{\mathrm{Y}}=5,5018+1,0892 * * \mathrm{~A}-0,3683 * \mathrm{~A}^{2}$ & 0,9356
\end{tabular}

* Significativo $(P<0,05)$ pelo teste ' $t$ ' (Significant $[P<.05]$ by $t$ test). ** Significativo $(P<0,01)$ pelo teste ' $\mathrm{t}$ ' (Significant $[P<.01]$ by $t$ test). quanto às proporções de colmo e panículas dos híbridos AGX-212 e AGX-213, de porte alto, que apresentaram relação $\mathrm{CF} / \mathrm{P}$ igual $(\mathrm{P}<0,01)$ ao híbrido de porte médio AGX-215. As frações colmo e panícula exerceram maior influência sobre a relação $\mathrm{CF} / \mathrm{P}$ que a fração folhas, visto que a $\mathrm{CF} / \mathrm{P}$ apresentou altas correlações com a porcentagem de colmo $\left(0,877^{* *}\right)$ e panículas $\left(-0,936^{* *}\right)$ e baixa correlação com a porcentagem de folhas $\left(0,092^{\mathrm{ns}}\right)$.

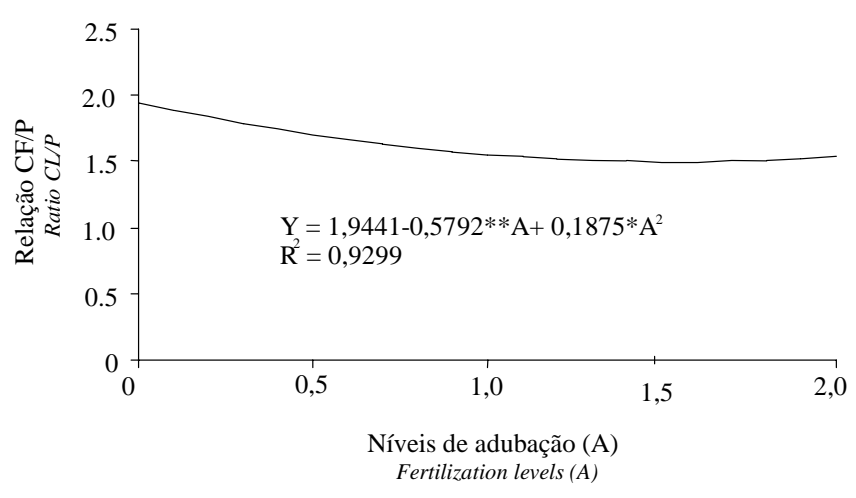

Figura 1 - Estimativas da relação colmo+folha/panícula $(C F / P)$, em função dos níveis de adubação (A).

Figure 1 - Estimates of stem+leaf/panicle ratio (CL/P), according to the fertilization levels $(A)$.

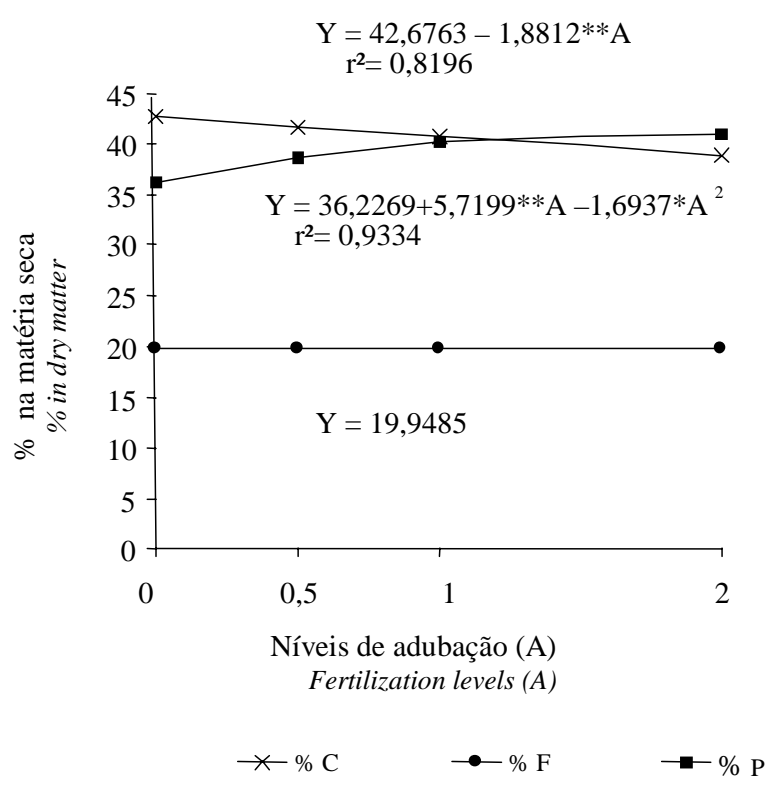

Figura 2 - Estimativa das porcentagens de colmo (\%C), folhas $(\% \mathrm{~F})$ e panículas $(\% \mathrm{P})$, com base na MS, em função dos níveis de adubação $(A)$, em recomendação/ha.

Figure 2 - Estimate of percentages of stem $(\% \mathrm{C})$, leaves $(\% L)$ and panicle $(\% P)$, on DM basis, according to the fertilization levels (A), in Recommendation/ha. 
A altura não sofreu variações com a adubação, verificando-se estimativa média igual a 3,1308 $\mathrm{m}$.

Não houve diferença $(\mathrm{P}>0,05)$ para a interação dos fatores híbrido x adubação para a produção de colmos, folhas e panículas. Para o fator adubação, observou-se efeito $(\mathrm{P}<0,01)$ apenas para a produção de MS de panículas. Ressalta-se a alta produtividade de colmo, folhas e panículas verificadas nas parcelas sem adubação, em função da alta fertilidade do solo e das condições climáticas favoráveis. As equações de regressão ajustadas para as produções de colmos (PSC), folhas (PSF) e de panículas (PSP) encontramse na Tabela 4.

A produção de MS de panículas apresentou resposta quadrática em função do nível de adubação, estimando-se valor máximo para o nível de 1,478 vezes a adubação recomendada $(517,3 \mathrm{~kg} / \mathrm{ha}$ da fórmula NPK 26-28-08). A maior produção de MS de panículas em função da adubação pode proporcionar maior produtividade de MS total e influenciar positivamente a qualidade da forragem produzida.

As estimativas da relação colmo+folhas/panícula (CF/P) e as proporções, com base na MS de colmos (\%C), folhas (\%F) e de panículas (\%P), em função dos níveis de adubação, encontram-se representadas nas Figuras 1 e 2.

A resposta da relação CF/P em função dos níveis de adubação, dentro da faixa avaliada, apresentou declínio até o nível de adubação de 1,544 vezes a recomendação (540,4 kg/ha de 26-28-08), estando associada, basicamente, à maior produção de panículas

Tabela 5 - Equações de regressão estimadas dos teores de matéria seca (MS) da planta inteira, de colmos (MSC), folhas (MSF) e panículas (MSP) dos híbridos, em função dos níveis de adubação (A), e coeficientes de determinação

Table 5 - Estimated regression equations of dry matter contents of whole plant, stem, leaves and panicle of the evaluated hybrids, according to the fertilization levels $(A)$, and coefficients of determination

\begin{tabular}{llc}
\hline $\begin{array}{l}\text { Variáveis } \\
\text { Variables }\end{array}$ & $\begin{array}{c}\text { Equações de regressão } \\
\text { Regression equations }\end{array}$ & $\mathrm{r}^{2}$ \\
\hline MS (\%) & $\hat{\mathrm{Y}}=27,8494+0,6277^{*} \mathrm{~A}$ & 0,6271 \\
MSC (\%) & $\hat{\mathrm{Y}}=20,6928$ & \\
MSF (\%) & $\hat{\mathrm{Y}}=29,7538$ & \\
MSP (\%) & $\hat{\mathrm{Y}}=52,8322$ & \\
\hline
\end{tabular}

Significativo $(P<0,05)$ pelo teste ' $t$ '.

Significant $(P<.05)$ by $t$ test.

R. Bras. Zootec., v.33, n.6, p.1975-1984, 2004 (Supl. 2) resultante da adubação, que apresentou valor máximo no nível da aplicação de 1,479 vezes a recomendação (517,6 kg/ha de 26-28-08).

O aumento na produção de panículas, em toneladas de MS/ha, com o acréscimo dos níveis de adubação, refletiu em maior porcentagem de panículas e, conseqüentemente, reduziu a porcentagem de colmos, uma vez que a porcentagem de folhas foi constante. Igualando-se as equações estimadas para porcentagem de colmos e de panículas, verifica-se que, dentro da faixa de adubação utilizada (abaixo de 1,136 vezes a adubação recomendada), a proporção de colmos será maior que a de panículas.

Os teores de matéria seca de colmos, folhas e panículas não apresentaram variações em relação aos níveis de adubação, entretanto foi observado avanço linear nos teores de matéria seca da planta inteira (Tabela 5), provavelmente graças à maior participação de panículas na massa total da forragem com o aumento nos níveis de adubação.

Os fatores híbrido e adubação apresentaram significância $(\mathrm{P}<0,01)$ para os teores de carboidratos solúveis (CHO) da planta inteira, expressos na MS e MV. Na Tabela 6, constam as médias dos teores de carboidratos solúveis da planta inteira, em porcentagem da MS e da MV, dos híbridos avaliados.

As médias de CHO obtidas estão acima dos níveis mínimos desejáveis, de 6 a 8\% da MS (Gourley \& Lusk, 1977) ou 2,5 a 3\% da matéria verde (Wilkinson, 1983; Petterson \& Lindgren, 1989), capazes de propiciar boa preservação da forragem. O

Tabela 6 - Médias dos teores de carboidratos solúveis ( $\mathrm{CHO}$ ) da planta dos híbridos avaliados, em porcentagens da matéria seca e da matéria verde

Table 6 - Means of soluble carbohydrates (CHO) of the plants of the evaluated hybrids, in \% dry matter and green matter

\begin{tabular}{lcc}
\hline $\begin{array}{l}\text { Híbrido } \\
\text { Hybrid }\end{array}$ & $\begin{array}{c}\text { CHO (\% na MS) } \\
\text { CHO (\% DM) }\end{array}$ & $\begin{array}{c}\text { CHO (\% na MV) } \\
\text { CHO (\% GM) }\end{array}$ \\
\hline AG-2002 & $19,80^{\mathrm{A}}$ & $4,91^{\mathrm{A}}$ \\
AG-2005E & $16,23^{\mathrm{B}}$ & $5,10^{\mathrm{A}}$ \\
AGX-202 & $13,71^{\mathrm{C}}$ & $4,08^{\mathrm{B}}$ \\
AGX-213 & $12,24^{\mathrm{C}}$ & $3,33^{\mathrm{C}}$ \\
AGX-215 & $12,89^{\mathrm{C}}$ & $3,73^{\mathrm{BC}}$ \\
\hline
\end{tabular}

Médias, nas colunas, seguidas por letras distintas, diferem pelo teste Tukey $(P<0,01)$.

Means, within acolumn, followed by different letters, differ $(P<.01)$ by Tukey test. 
híbrido AG-2002 apresentou o maior $(\mathrm{P}<0,01)$ teor de CHO solúvel, com base na MS, entretanto, por ter menor teor de MS (24,72\%), apresentou teor de CHO solúvel, com base na $\mathrm{MV}$, igual $(\mathrm{P}>0,01)$ ao AG-2005E.

Os teores de carboidratos solúveis, com base na matéria seca (CHO/MS) e na matéria verde $(\mathrm{CHO} /$ $\mathrm{MV}$ ), aumentaram linearmente em função do nível de

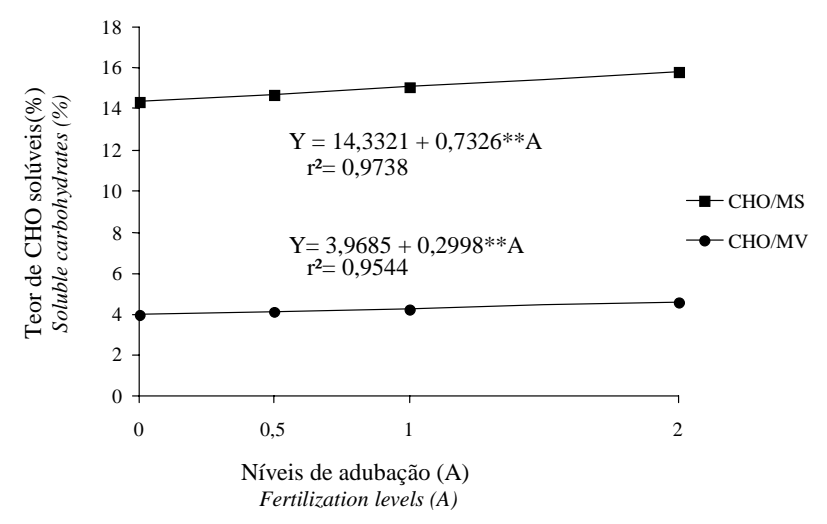

Figura 3 - Estimativa dos teores de carboidratos solúveis da planta, em porcentagens da matéria seca (CHO/MS) e da matéria verde ( $\mathrm{CHO} / \mathrm{MV})$, em função dos níveis de adubação (A).

Figure 3 - Estimates of soluble carbohydrates (CHO) contents of the plant, in \% dry matter (CHO/MS) and green matter (CHO/MV), according to the fertilization levels $(A)$.

Tabela 7 - Médias dos teores de fibra em detergente neutro (FDN), fibra em detergente ácido (FDA), hemicelulose (HEMI), celulose (CEL) e lignina (LIG) da planta dos híbridos avaliados, em porcentagem da MS

Table 7 - Means of neutral detergent fiber (NDF), acid detergent fiber (ADF), hemicellulose (HEM), cellulose (CEL) and lignin (LIG) of the plant of the evaluated hybrids, in \% dry matter

\begin{tabular}{lcclll}
\hline Híbrido & FDN(\%) & FDA(\%) & HEM(\%) CEL(\%)LIG(\%) \\
Hybrid & $N D F$ & ADF & & & \\
\hline AG-2002 & $57,38^{\mathrm{c}}$ & $28,36^{\mathrm{b}}$ & $28,56^{\mathrm{bc}}$ & $21,66^{\mathrm{b}}$ & $6,04^{\mathrm{b}}$ \\
AG-2005E & $59,41^{\mathrm{b}}$ & $25,29^{\mathrm{c}}$ & $33,87^{\mathrm{a}}$ & $19,20^{\mathrm{c}}$ & $6,37^{\mathrm{a}}$ \\
AGX-212 & $59,40^{\mathrm{b}}$ & $30,78^{\mathrm{a}}$ & $28,56^{\mathrm{bc}}$ & $24,34^{\mathrm{a}}$ & $6,13^{\mathrm{b}}$ \\
AGX-213 $^{\text {AGX-215 }}$ & $62,30^{\mathrm{a}}$ & $31,56^{\mathrm{a}}$ & $30,74^{\mathrm{b}}$ & $24,28^{\mathrm{a}}$ & $6,11^{\mathrm{b}}$ \\
AGX $^{\mathrm{b}}$ & $31,48^{\mathrm{a}}$ & $29,75^{\mathrm{bc}}$ & $23,93^{\mathrm{a}}$ & $6,51^{\mathrm{a}}$ \\
\hline
\end{tabular}

Médias, nas colunas, seguidas por letras distintas, diferem pelo teste Tukey $(\mathrm{P}<0,05)$.

Means, within acolumn, followed by different letters, differ $(P<.05)$ by Tukey test.

R. Bras. Zootec., v.33, n.6, p.1975-1984, 2004 (Supl. 2) adubação (Figura 3), registrando-se, respectivamente, incrementos de 0,7326 e $0,2998 \%$ no teor de $\mathrm{CHO}$ solúvel, por variação unitária na adubação recomendada, provavelmente decorrentes de maior metabolismo da planta, proporcionado pela maior disponibilidade de nutrientes. Ressalta-se que, mesmo no nível de adubação zero, os teores de CHO solúveis presentes na forragem são suficientes para propiciar uma boa fermentação, garantindo sua conservação por meio de ensilagem.

Não foi verificado efeito $(\mathrm{P}>0,05)$ para a interação híbrido $\mathrm{x}$ adubação sobre os teores de fibra em detergente neutro (FDN), fibra em detergente ácido (FDA), hemicelulose (HEMI), celulose (CEL) e lignina (LIG) da planta inteira (Tabela 7). No entanto, observou-se efeito significativo do fator híbrido, para todas as variáveis supra-citadas, e do fator adubação, para FDN, FDA e HEMI e CEL.

Cabe ressaltar que o híbrido AG-2002 apresentou menor teor médio de FDN na forragem, mesmo em relação ao AG-2005 E, que apresenta menores proporções de colmos e de folhas na forragem, fato verificado por Neumann et al. (2002), que avaliaram a forragem dos híbridos AG-2002, AG-2005E, AGX213 e AGX-217, registrando teores de FDN de 48,38; 51,$90 ; 55,55$ e $58,16 \%$, respectivamente.

Neumann et al. (2002), avaliando a silagem destes híbridos constataram elevação nos teores de FDN em relação ao material original, com aumento mais significativo observado para o AG-2002, que passou a apresentar um teor de FDN na silagem superior ao AG-2005E (55,44 x 55,39\%, respectivamente), sendo o acréscimo relativo da fração fibrosa do material ensilado justificado pela fermentação e pelas perdas de sólidos solúveis via efluentes, fato também verificado com o presente material quando ensilado (Cândido et al., 2002). Assim, apenas a análise bromatológica da forragem original pode não permitir a realização de inferências acuradas sobre o valor nutricional de sua silagem, sugerindo a necessidade de ensaios avaliando o consumo e o desempenho animal.

Os teores de FDA, HEMI, CEL e LIG mantiveramse dentro da faixa de variação reportada na literatura, entretanto, observaram-se teores relativamente baixos de FDA e altos de HEMI, possivelmente em razão do uso da técnica de determinação seqüencial, pois a extração prévia com detergente neutro pode solubilizar alguns compostos que não seriam solubilizados apenas pelo detergente ácido (Van Soest, 1994). A fibra em detergente ácido apresenta-se inversamente relacionada à digestibilidade da forragem (Van Soest, 1994). 
Tabela 8 - Equações de regressão estimadas para os teores de FDN, FDA, hemicelulose (HEMI), celulose (CEL) e lignina (LIG) da planta, em porcentagem da MS, em função dos níveis de adubação $(A)$, e coeficientes de determinação

Table 8 - Estimated regression equations of NDF, ADF, hemicellulose (HEMI), cellulose (CEL) and lignin (LIG) of the plant, in \%DM, according to the fertilization levels (A), and coefficients of determination

\begin{tabular}{llc}
\hline $\begin{array}{l}\text { Variáveis } \\
\text { Variables }\end{array}$ & $\begin{array}{l}\text { Equações de regressão } \\
\text { Regression equations }\end{array}$ & $\mathrm{r}^{2}$ \\
\hline FDN(\%) & $\hat{\mathrm{Y}}=61,3874-1,6907 * * \mathrm{~A}$ & 0,9588 \\
NDF & $\hat{\mathrm{Y}}=29,4900$ & \\
FDA (\%) & & \\
ADF & $\hat{\mathrm{Y}}=31,3869-1,1981^{* *} \mathrm{~A}$ & 0,7431 \\
HEMI $(\%)$ & $\hat{\mathrm{Y}}=22,6810$ & \\
CEL $(\%)$ & $\hat{\mathrm{Y}}=6,0334$ & \\
LIG $(\%)$ &
\end{tabular}

Significativo $(\mathrm{P}<0,01)$ pelo teste ' $\mathrm{t}$ '.

Significant $(P<.01)$ by $t$ test.

Os valores de rendimento forrageiro e de teores de proteína bruta (PB) e digestibilidade in vitro da matéria seca (DIVMS) dos materiais avaliados foram apresentados e discutidos por Gontijo Neto et al. (2002). Os dados registrados foram utilizados, no presente trabalho, para a determinação de correlações lineares. Observou-se correlação linear $\left(-0,65^{* *}\right)$ entre FDA e DIVMS, fato também confirmado pelo comportamento dos híbridos AG-2005E e AGX-213, que apresentaram menor e maior teores de FDA (25,29 e $31,56 \%)$ e maior e menor de DIVMS (61,69 e 53,79\%).

Os teores de lignina também relacionados negativamente com a digestibilidade da forragem, mesmo apresentando diferenças significativas, pouco diferiram, em valores absolutos entre os híbridos avaliados.

$\mathrm{Na}$ Tabela 8, encontram-se as equações de regressão estimadas para os teores de FDN, FDA, HEMI, CEL e LIG, em função dos níveis de adubação (A) e os respectivos coeficientes de determinação. Apenas a FDN e a hemicelulose foram afetadas pelas adubações.

Os teores de FDN diminuíram de forma linear à taxa de $1,6907 \%$ para cada unidade aumentada no nível de adubação. Este decréscimo era esperado, em virtude dos resultados verificados nas frações solúveis da forragem, como o aumento de CHO solúveis e de proteína com o aumento do nível de adubação. Menores valores de FDN podem influir positivamente, elevando o consumo animal, quando não há outros fatores envolvidos.

\section{Conclusões}

Aumento nos níveis de adubação proporcionou maior produção de panículas, refletindo na diminuição da relação colmo + folha/panícula, na maior proporção de panículas e no teor de MS da planta inteira.

Os híbridos apresentaram diferenças significativas entre os teores de carbohidratos solúveis, de fibra e de carboidratos estruturais, indicando a necessidade de estudos avaliando o consumo e o desempenho animal da silagem destes materiais. $\mathrm{O}$ aumento nos níveis de adubação resultou em queda nos teores de FDN e de hemicelulose.

Os híbridos avaliados apresentaram diferentes proporções de colmos, de folhas e panículas, sendo colmos diretamente e panículas inversamente correlacionadas com a altura. O teor de matéria seca da planta inteira foi fortemente influenciado pelas proporções de colmos e de panículas, tendo as panículas apresentado os maiores teores de MS e colmos, os menores.

\section{Literatura Citada}

ASSOCIATION OF OFFICIAL ANALYTICAL CHEMISTS AOAC. Official methods of analysis. 15.ed. Arlington, 1990. v.1, 1117p.

BORGES, A.L.C.C.; GONÇALVES, L.C.; RODRIGUEZ, N.M. et al. Qualidade de silagens de híbridos de sorgo de porte alto, com diferentes teores de tanino e de umidade no colmo. Arquivo Brasileiro de Medicina Veterinária e Zootecnia, v.49, n.4, p.441-452, 1997.

BRUNO, O.A.; ROMERO, L.A.; GAGGIOTTI, M.C. et al. Cultivares e sorgos forrajeros para silaje. 1. Rendimiento de materia seca y valor nutritivo de la planta. Revista Argentina Producción Animal, v.12, n.2, p.157-162, 1992.

CÂNDIDO, M.J.D.; OBEID, J.A.; PEREIRA, O.G. et al. Valor nutritivo de híbridos de sorgo (Sorghum bicolor (L.) Moench) sob doses crescentes de adubação. Revista Brasileira de Zootecnia, v.31, n.1, p.20-29, 2002.

COMISSÃO DE FERTILIDADE DO SOLO DO ESTADO DE MINAS GERAIS. Recomendações para uso de corretivos e fertilizantes em Minas Gerais. 4 Aproximação. Lavras: 1989. 159p.

FARIA, V.P. Técnicas de produção de silagens. In: SIMPÓSIO SOBRE MANEJO DE PASTAGENS, 8., 1986, Piracicaba. Anais... Piracicaba: Fundação de Estudos Agrários Luiz de Queiroz, 1986. 340p.

GOMIDE, J.A.; ZAGO, C.P.; CRUZ, M.E. Milho e sorgo em cultivos puros ou consorciados com soja, para produção de silagem. Revista Brasileira de Zootecnia, v.16, n.4, p.308-317, 1987. 
GONTIJO NETO, M.M. Rendimento e valor nutritivo de híbridos de sorgo (Sorghum bicolor (L.) Moench) sob níveis crescentes de adubação. Viçosa, MG: Universidade Federal de Viçosa, 2000. 68p. Dissertação (Mestrado em Zootecnia) - Universidade Federal de Viçosa, 2000.

GONTIJO NETO, M.M.; OBEID, J.A.; PEREIRA, O.G. et al. Híbridos de sorgo (Sorghum bicolor (L.) Moench) cultivado sob níveis crescentes de adubação. Rendimento, proteína bruta e digestibilidade in vitro. Revista Brasileira de Zootecnia, v.31, n.4, p.1640-1647, 2002.

GOURLEY, L.M.; LUSK, F.W. Sorghum silage quality as affected by soluble carbohydrate, tannins and other factors. In: ANNUAL CORN AND SORGHUM RESERCH COnference, 32., 1977, Mississipi. Proceedings... Mississipi: Mississipi State University, 1977. p.157-170.

HAIGH, P.M. Effect of herbage wather-soluble carbohydrate content and weather conditions at ensilage on the fermentation of grass silages made on commercial farms. Grass Forage Science, v.45, n.3, p.263-271, 1990.

HENDERSON, N. Silage additives. Animal Feed Science and Technology, v.45, n.1, p.35-56, 1993.

JOHNSON, R.R.; FARIA, V.P.; McCLURE, K.E. Effects of maturity on chemical composition and digestibility of bird resistant sorghum plants when fed to sheep as silages. Journal of Animal Science, v.33, n.5, p.1102-1109, 1973.

MALAVOLTA, E.; DANTAS, J.P. Nutrição e adubação de milho. In: PATERNIANE, E.; VIEGAS, G.P. (Eds.) Melhoramento e produção de milho. 2.ed. Campinas: Fundação Cargill, 1987. v.2, p.539-593.

McBEE, G.G.; MILLER, F.R. Carbohydrates in sorghum culms as influenced by cultivars, spacing, maturity over a diurnal period. Crop Science, v.22, n.1-2, p.381-385, 1982.

McDOnAlD, P.; HENDERSON, A.R.; HERON, S. The biochemistry of silage. 2.ed. Marlow: Chalcombe, 1991. 340p.

MINSON, D.J. Forage in ruminant nutrition. Agronomy Journal, v.82, n.7, p.687-690, 1990.
NEUMANN, M.; RESTLE, J.; ALVES FILHO, D.C. et al. Avaliação do valor nutritivo da planta e da silagem de diferentes híbridos de sorgo (Sorghum bicolor (L.) Moench). Revista Brasileira de Zootecnia, v.31, n.1, p.293-301, 2002 (Suplemento).

OBEID, A.J.; GOMIDE, J.A.; CRUZ, M.E. et al. Silagens consorciadas de milho (Zea may L.) com leguminosas: produção e composição bromatológica. Revista Brasileira de Zootecnia, v.21, n.1, p.33-38, 1992.

PETTERSON, K.L.; LINDGREN, S. The influence of the carbohydrate fraction and additives on silage quality. Grass Forage Science, v.45, n.2, p.223-233, 1989.

SCHIMID, A.R.; GOODRICH, R.D.; JORDAN, R.M. Relationships among agronomic characteristics of corn and sorghum cultivars and silage quality. Agronomy Journal, v.68, n.2, p.403-406, 1976.

SILVA, D.J. Análise de alimentos (métodos químicos e biológicos). Viçosa, MG: Universidade Federal de Viçosa, 1990. 166p.

UNIVERSIDADE FEDERAL DE VIÇOSA - UFV. SAEG (Sistema da Análises Estatística e Genéticas). Viçosa, MG, 1995. (Versão 5.0).

Van SOEST, P.J. Nutritional ecology of ruminant. 2.ed. Ithaca: Cornell, 1994. 476p.

WILKINSON, J.M. Silages made from tropical and temperate crops. 1. The ensiling process and its influence on the feed value. World Animal Review, v.45, n.46, p.36-42, 1983.

ZAGO, C.P. Cultura de sorgo para produção de silagem de alto valor nutritivo. In: SIMPOSIO SOBRE NUTRIÇÃO DE BOVINOS, 4., 1991, Piracicaba. Anais... Piracicaba: Fundação de Estudos Agrários “Luis de Queiroz”, 1991. p.169-217.

Recebido em: 22/02/03 Aceito em: 16/08/04 